\title{
Extending the geographic and altitudinal range of Popilius gibbosus (Burmeister, 1847) (Coleoptera: Passalidae) with taxonomical comments
}

\author{
Marcus Bevilaqua ${ }^{1,2}$ \& Claudio Ruy Vasconcelos da Fonseca ${ }^{1,3}$ \\ 1 Instituto Nacional de Pesquisas da Amazônia (INPA), Coordenação de Biodiversidade (CBIO), \\ Laboratório de Sistemática e Ecologia de Coleoptera (LASEC). Manaus, AM, Brasil. \\ ${ }^{2}$ ORCID: https://orcid.org/0000-0003-2863-5115. E-mail: marcusbevilaqua@gmail.com \\ 3 ORCID: https://orcid.org/0000-0002-1955-288X. E-mail: rclaudio@inpa.gov.br
}

\begin{abstract}
Popilius gibbosus (Burmeister, 1847) was known only from localities in the Cordillera Oriental of the northern Andes in Colombia and Venezuela and the southern section in Colombia between 1,350-3,000 m. Herein, we provide the first record for Bolivia at low elevations $(<1,000 \mathrm{~m})$, thus extending the geographic and altitudinal range of this species. Information about characters not yet used and the first description of the aedeagus are provided, accompanied with figures of those characters that facilitate the identification of the species. An identification key for Popilius species in Bolivia and a P. gibbosus distribution map are also provided.
\end{abstract}

Keywords. Amazon Andean; Andes; Saproxilophagus beetles; Range distribution; South America; Taxonomy.

\section{INTRODUCTION}

Popilius Kaup, 1871 is a Neotropical genus of Passalidae belonging to the Proculini tribe which, according to the most recent concept promoted by Boucher (2006), comprises 15 species, distributed from the intertropical region of South America, including Trinidad and the Isthmus of Panama. Based on a phylogenetic analysis for Proculini, Boucher (2006) considered the genus a natural group supported by one autapomorphy: the lower apical spines of the meso- and metatibiae with a beveled apex. However, Beza-Beza et al. (2020) do not corroborate this hypothesis, claiming that Popilius species are mixed with others of Petrejoides Kuwert, 1896.

Boucher (2006) still considered that the genus is subdivided into two groups of species with morphological and biogeographic differences: the "marginatus" group, extra-Andean, dependent on low to medium altitudinal forests $(<1,500 \mathrm{~m})$; and the "hebes" group, intra-Andean north (from 1,000 to more than $3,000 \mathrm{~m}$ above sea level). Gillogly (2005) also reported that almost all species of Popilius have an extremely limited range in distance or altitude.

The second group includes Popilius gibbosus (Burmeister, 1847) with distribution on the eastern north Andean face between 1,350 and 3,000 m (Gillogly, 2005; Boucher, 2006; Jiménez-Ferbans et al., 2018). Gillogly (2005) was the only author to carry out a taxonomic review for the genus, which unfortunately was not published in indexed and peer-reviewed journals. However, it has added significant information to the taxonomic knowledge of the genus. In his work, Gillogly (2005) commented that $P$. gibbosus forms a complex of seven species, all being synonyms with a single species (P. gibbosus) with morphological variations.

As this species is still the subject of discussions regarding morphological characters used for its identification and with restricted geographical distribution, the present work aims to formally carry out the first record of the occurrence of Popilius gibbosus for Bolivia. Thus, expanding the geographical and altitudinal distribution of the species, now in a lower altitude region $(<1,000 \mathrm{~m})$ and provide a detailed diagnosis, containing images that help to visualize the main taxonomic characters.

\section{MATERIAL AND METHODS}

The analyzed material comes from the Laboratório de Sistemática e Ecologia de 
Coleoptera (LASEC) of the Instituto Nacional de Pesquisas da Amazônia (INPA). The specimens of $P$. gibbosus were identified using the the original description by Burmeister (1847), taxonomic revision by Gillogly (2005), and the diagnosis present in Jiménez-Ferbans et al. (2018) for Colombian specimens. The terminology

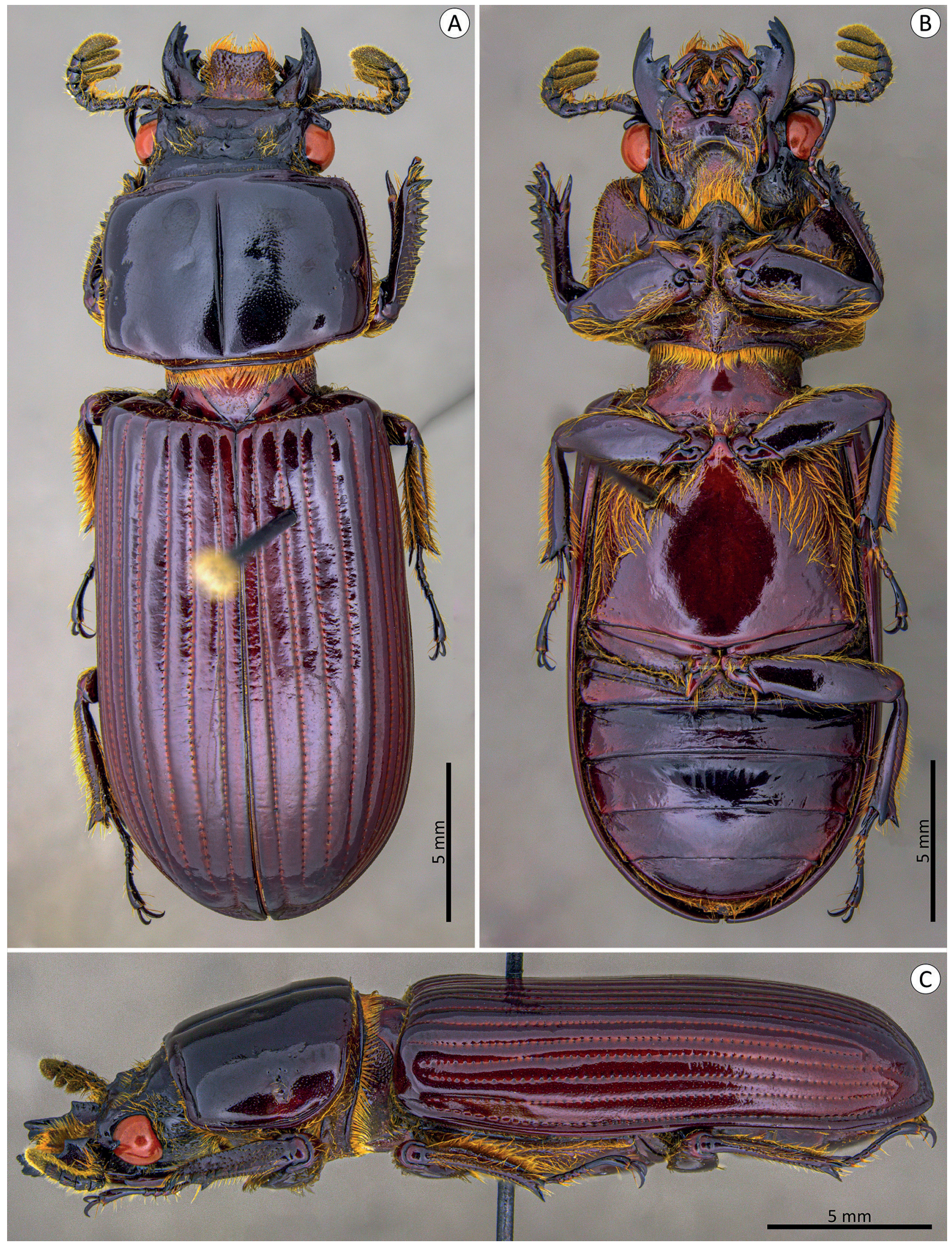

Figure 1. Popilius gibbosus (Burmeister, 1847), habitus. (A) dorsal; (B) ventral; (C) lateral. 
for the cephalic capsule and mandibles follows Boucher (2006), and to other parts of the body, it follows ReyesCastillo (1970).

The images were obtained in a Leica M165C stereomicroscope with a coupled DFC295 camera and processed in the LAS Version 4.2 software to perform the morphometric measurements. Then, they were stacked in layers by the software Helicon Focus Version 7.6.1 to generate a single image of combined focus. For uniform and more effective illumination, we used the geodesic dome of lighting according to Kawada \& Buffington (2016). The images were edited for light and contrast correction, and the figures were made using Adobe Photoshop, following the guide proposed by Bevilaqua (2020). The distribution map was produced with aid of the website SimpleMappr (Shorthouse, 2010).

\section{RESULTS}

\section{Popilius gibbosus (Burmeister, 1847)} Figs. 1-2

Passalus gibbosus Burmeister, 1847: 507.

Pertinax gibbosus: Kaup, 1869: 21.

Popilius gibbosus: Kaup, 1871: 76; Kuwert, 1897: 299; Hincks \& Dibb, 1935: 17; Reyes-Castillo, 1970: 107; Jiménez-Ferbans et al., 2018: 17.

Oileoides gibbosus: Pereira, 1941: 99; Hincks \& Dibb, 1958: 7.

Material examined: BOLIVIA: Region Chapare - $400 \mathrm{~m}$, 06-ix-58, leg. Zischka // Popilius gibbosus (Burmeister, 1847) M. Bevilaqua det. 2020. $1 \sigma^{\Upsilon}$ (INPA). Bolivia oriental, Santa Cruz - 500 m, 24-xi-55, Zischka // Popilius gibbosus (Burmeister, 1847) M. Bevilaqua det. 2020. 1 \& (INPA).

Diagnosis: medium-sized specimens (24.5-26 mm), body flat (Fig. 1). Labrum with a concave anterior edge; clypeus large and wide with slightly concave anterior edge, with anterior angles large and acute; posterior angles large, almost fused with mediofrontal tubercles; clypeofrontal groove strong (Fig. 2A). Frontal area straight or slightly convex, finely punctate. Posterior mediofrontal area with longitudinal groove and that extends until the central tubercle. Posterofrontal ridges weak, flat, straight, reaching the inner tubercles, which are inconspicuous. Central tubercle small, with apex not free, and deep groove on posterior region, fused and placed behind the lateroposterior tubercles, which are large, well-marked, and transverse. Lateropostfrontal areas shallow, with pubescent punctation. Canthus ocular with apex rounded, not reaching middle of eye. Antennal club with three large and narrow lamellae (Fig. 2A). Central area of mentum not dilated, glabrous, impunctate; sides with large and shallow scars. Hypostomal process glabrous and convex laterally, without longitudinal groove (Fig. 2B). Prothorax pubescent ventrally (Fig. 1B); anterior angles of prothorax rounded, not protruding (Figs. 1A, 2C); pronotal punctation present only on lateral fossae, with presence of short setae (Fig. 1C). Marginal pronotal groove wide, deep and impunctate, practically reaching the longitudinal groove (Fig. 2C). Prosternal process rhomboidal, with long and sparse setae (Fig. 2D). Mesosternal scars narrow, shallow, glabrous, with opaque surface (Fig. 2D). Metasternal disc not delimited by punctuations; metasternum without punctures on posterior region and densely pubescent laterally (Fig. 2E). Humeri glabrous. Aedeagus slightly longer than wide; median lobe globose, slightly larger than basal piece and parameres together, and strongly sclerotized ventrally. Parameres smaller than basal piece, separated by a conspicuous suture (except centrally) ventrally. In dorsal view, projections of the parameres are not joined. The sclerotization of basal piece is truncate laterally, and membranous toward dorsal surface (Fig. 2F).

Distribution: Colombia (Boyacá, Cundinamarca, Magdalena, Meta, Valle del Cauca), Venezuela (Aragua, Trujillo) (Gillogly, 2005; Jiménez-Ferbans et al., 2018); Bolivia (Cochabamba, Santa Cruz) (Fig. 3).

Remarks: According to Gillogly (2005) and JiménezFerbans et al. (2018), Popilius gibbosus is restricted to high-altitudes $(1,350-3,000 \mathrm{~m})$ in eastern portion of the Andes of Colombia and Venezuela. The specimens from Bolivia were collected at the slope of the eastern portion of the Cordillera at low altitudes (400 $\mathrm{m}$ and $500 \mathrm{~m}$ ). This makes it possible to expand both the information on the distribution and the altitude at which this species can be found, being able to assist in the collection of this species, which is relatively rare in several collections.

Also, according to Gillogly (I.c.), the absence of specimens from the western Cordillera and the Central Cordillera may be an effect of the lack of collection, as mentioned by Jiménez-Ferbans et al. (2019) referring to Bolivia's bess beetle fauna. Jiménez-Ferbans et al. (2019) carried out a checklist of Passalidae species from Bolivia, finding two Popilius species: P. marginatus (Percheron, 1835) and $P$. tetraphyllus (Eschscholtz, 1829). The authors commented that the number of species of Bolivia is low and reflects the lack of a systematic exploration of this country; more surveys are needed, especially in ecosystems such as montane forest and tropical rain forest, pointing out the need for sampling in the mid-range montane ecosystems of Bolivia (Jiménez-Ferbans et al., 2019).

\section{Key to Popilius species from Bolivia (Adapted from Jiménez-Ferbans et al., 2019)}

1. Antennal club with three lamellae..........................................................2

1'. Antennal club with four or five lamellae ...Popilius tetraphyllus (Eschscholtz, 1829)

2. Metasternum glabrous anterolaterally . ..Popilius marginatus (Percheron, 1835)

2. Metasternum pubescent anterolaterally Popilius gibbosus (Burmeister, 1847) 


\section{DISCUSSION}

Gillogly (2005) commented that $P$. gibbosus forms a complex of seven species that must be treated as synonyms. He also commented that there are subtle morphological variations between the species studied (including type specimens), but that such variations are not sufficient to distinguish the species to the point of being treated as different. The characters used by Gillogly in his review agree with those of our specimens, except for the presence of setae on the hypostomal process, elytral humeri, and on the last abdominal segment, which are absent in the specimens we have. In the diagnosis provided by Jiménez-Ferbans et al. (2018) the only character that does not match our specimens are the antennal clubs, which according to the authors are short, although in the
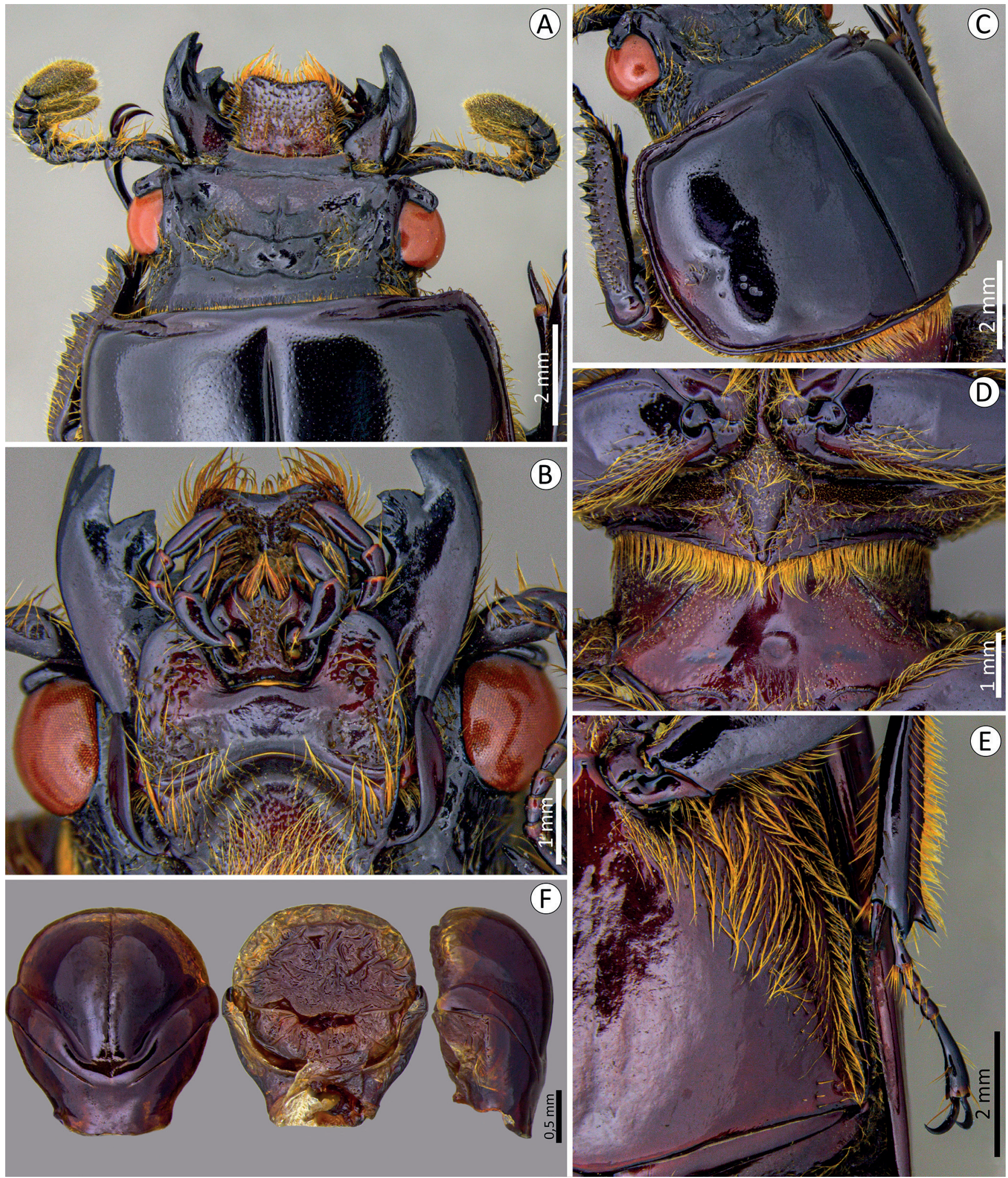

Figure 2. Popilius gibbosus (Burmeister, 1847). (A) Head and prothorax, dorsal; (B) Head, ventral (C) Head and prothorax, dorsolateral; (D) Prosternal process and mesosternum; (E) Metasternum (left side); (F) Aedeagus (ventral, dorsal and lateral view). 


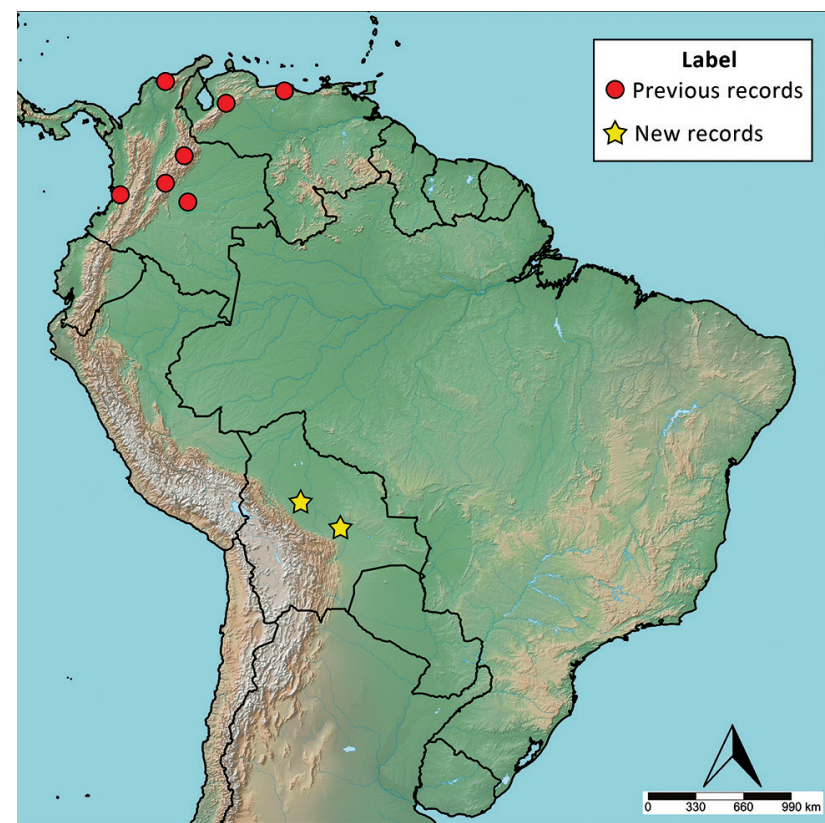

Figure 3. Geographical distribution of Popilius gibbosus (Burmeister, 1847) in South America, with previous and new records.

image available in the work it is possible to observe that they are long and thin, similar to our specimens.

Gillogly (2005) did not explore characters from the aedeagus, although male genitalia has already proved useful in the identification of species, groups of species, or genera (Reyes-Castillo, 1970; Bührnheim, 1978; Cano, 1994; Boucher, 2006). The aedeagus of $P$. gibbosus, which has not been described so far, does not resemble any other known in the literature, making this an excellent structure to differentiate the species from the others in the genus.

In a phylogenetic analysis proposed by Beza-Beza et al. (2020) that aimed to understand the relationships between the genera of New World Passalidae, Popilius was not rescued as a monophyletic group, becoming paraphyletic concerning Petrejoides. Popilius gibbosus, one of the species used in the analysis, was recovered as a sister group of Petrejoides tenius Kuwert, 1896. Therefore, as other authors (Gillogly, 2005; Beza-Beza et al., 2020) have already suggested, there is a need for an extensive taxonomic review accompanied by phylogenetic analysis of Popilius to clarify the limits of the genus and the species that are included in it. We hope that the information available here may help to resolve this issue in the future.

AUTHORS' CONTRIBUTIONS: MB: Conceptualization, Methodology, Visualization, Data curation, Formal analysis, Investigation, Writing - original draft. CRVF: Supervision. MB, CRVF: Writing - review \& editing. All authors actively participated in the discussion of the results, they reviewed and approved the final version of the paper.

CONFLICTS OF INTEREST: Authors declare there are no conflicts of interest.

FUNDING INFORMATION: The first author is grateful to Coordenação de Aperfeiçoamento de Pessoal de Nível
Superior (CAPES) for the doctorate scholarship to support this research project (number process: 001/2015).

ACKNOWLEDGMENTS: We would like to thank the reviewers for providing important considerations to the article.

\section{REFERENCES}

Bevilaqua, M. 2020. Guide to image editing and production of figures for scientific publications with an emphasis on taxonomy Image editing for scientific publications. Zoosystematics and Evolution, 96(1): 139-158. https://doi.org/10.3897/zse.96.49225.

Beza-Beza, C.F.; Jiménez-Ferbans, L. \& McKenna, D.D. 2020. Phylogeny and Systematics of Wood-Degrading Neotropical Bess Beetles (Coleoptera: Passalidae: Passalinae). Arthropod Systematics \& Phylogeny, 78(2): 287-308. https://doi.org/10.26049/ASP78-2-2020-05.

Boucher, S. 2006. Évolution et phylogénie des Coléoptères Passalidae (Scarabaeoidea). Annales de la Société Entomologique de France, N.S., 41(3/4): 239-604.

Bührnheim, P.F. 1978. 0 edeago na sistemática de passalídeos americanos (Coleoptera: Passalidae). Acta Amazonica, 8(1): 5-61.

Burmeister, H. 1847. Handbuch der Entomologie: Besondere Entomologie, Fortsetzung: Coleoptera Lamellicornia Xylophila et Pectinicornia. Berlin, $\mathrm{G}$. Reimer. v. 5, viii + 584p.

Cano, E.B. 1994. Estado actual sobre el conocimiento del edeago en Passalidae (Coleoptera), con la descripción del edeago en seis especies del Viejo Mundo. Acta Zoológica Mexicana (nueva serie), 61: 21-34.

Gillogly, A.R. 2005. Review of the Genus Popillius and preliminary phylogeny of Passalidae (Coleoptera). - Texas A\&M University, Texas, USA. PhD Dissertation.

Hincks, W.D. \& Dibb, J.R. 1935. Coleopterorum catalogus. Pars 142: Passalidae. $s^{\prime}$ Gravenhage, W. JUNK. 118p.

Hincks, W.D. \& Dibb, J.R. 1958. Coleopterorum catalogus. Suplementa Pars 142: Passalidae. 'sGravenhage, Uitgevery Dr. W. JUNK. 32p.

Jiménez-Ferbans, L.; Reyes-Castillo, P.; Schuster, J.C. 2018. Passalidae (Coleoptera: Scarabaeoidea) of the Biogeographical Province of Choco and the West Andean Region of Colombia, with the Description of Two New Species. Neotropical Entomology, 47(5): 642-667. https://doi. org/10.1007/s13744-017-0584-1.

Jiménez-Ferbans, L.; Reyes-Castillo, P.; Schuster, J.C. 2019. The Passalidae (Coleoptera, Scarabaeoidea) from Bolivia, with the descriptions of three new species. ZooKeys, 882: 51-85. https://doi.org/10.3897/ zookeys.882.35532.

Kaup, J.J. 1869. Prodromus zu einer Monographie der Passaliden. Coleopterologische Hefte, 4: 1-40.

Kaup, J.J. 1871. Monographie der Passaliden. Berliner Entomologische Zeitschrift, 15: 1-125.

Kawada, R. \& Buffington, M.L. 2016. A scalable and modular dome illumination system for scientific microphotography on a budget. PloS One, 11(5): e0153426. https://doi.org/10.1371/journal.pone.0153426.

Kuwert, A. 1897. Die Passaliden Dichotomisch Bearbeitet. Novitates Zoologicae, 4: 274-306.

Pereira, F.S. 1941. Contribuição para o conhecimento da subfamília dos Pseudacanthinae (Col. Passalidae). Arquivos de Zoologia do Estado de São Paulo, 3(5): 93-113.

Reyes-Castillo, P. 1970. Coleoptera, Passalidae: morfología e división em grandes grupos; géneros Americanos. Folia Entomológica Mexicana, 20-22: 1-240.

Shorthouse, D.P. 2010. SimpleMappr, an online tool to produce publicationquality point maps. [Retrieved from https://www.simplemappr.net] 